\title{
Red sorrel (Hibiscus Sabdariffa) prevents the ethanol-induced deficits of Purkinje cells in the cerebellum
}

\author{
Suryanti $\mathrm{S}^{1,2}$, Partadiredja $\mathrm{G}^{2}$, Atthobari $\mathrm{J}^{3}$ \\ Department of Physiology, Faculty of Medicine, Universitas Gadjah Mada, Yogyakarta, Indonesia. \\ gpartadiredja@yahoo.com
}

\begin{abstract}
Objectives: The present study is aimed at investigating the possible protective effects of $H$. sabdariffa on ethanol-elicited deficits of motor coordination and estimated total number of the Purkinje cells of the cerebellums of adolescent male Wistar rats.

Methods: Forty male Wistar rats aged 21 days were divided into five groups. Na/wtr group was given water orally and injected with normal saline intra peritoneally (ip). Eth/wtr group was given water orally and ethanol (ip). Another three experimental groups (Eth/Hsab) were given different dosages of $H$. sabdariffa and ethanol (ip). All groups were treated intermittently for the total period of treatment of two weeks. The motor coordination of rats was tested prior and subsequent to the treatments. The rats were euthanized, and their cerebellums were examined. The total number of Purkinje cells was estimated using physical fractionator method.

Results: Upon revolving drum test, the number of falls of rats increased following ethanol treatment. There was no significant difference between the total number of falls prior and subsequent to treatment in all Eth/Hsab groups. The estimated total number of Purkinje cells in Eth/Hsab groups was higher than in Eth/wtr group.

Conclusion: $H$. sabdariffa may prevent the ethanol-induced deficits of motor coordination and estimated total number of Purkinje cells of the cerebellums in adolescent rats (Tab. 3, Fig. 1, Ref. 42). Text in PDF www.elis.sk. Key words: alcohol, antioxidant, rotarod.
\end{abstract}

\section{Introduction}

Epidemiological studies have revealed that males drink more ethanol than females (1). Particularly adolescents show drinking behavioural patterns which cause profound public health concern (2). Immediate or late effects of tragic fatal injuries (such as traffic accidents, falls, drowning, etc.) due to early age ethanol consumptions are commonly observed. Male adolescents also more frequently drink to intoxication compared to their female counterparts (1), and hence are more vulnerable to detrimental consequences of ethanol. Such consequences may arise from the ethanol-induced dysfunction of the central nervous system, including the cerebellum. Chronic ethanol intoxication may bring about motor coordination and balance disturbance $(3,4)$, structural (5-9) and biochemical alterations in the cerebellum of both human subjects and animal models. Pascual et al (10) reported that intermittent intra-peritoneal injection of ethanol in adolescent rats that mimicked intermittent binge ethanol consumption frequently occurs amongst adolescents, significantly increased the apoptosis of brain cells, including the cerebellar neurons. In addition, this

${ }^{1}$ Ministry of Health Polytechnic Semarang, Indonesia, and ${ }^{2}$ Department of Physiology and ${ }^{3}$ Department of Pharmacology and Therapy, Faculty of Medicine, Universitas Gadjah Mada, Yogyakarta, Indonesia

Address for correspondence: G. Partadiredja, Department of Physiology, Faculty of Medicine, Universitas Gadjah Mada, Yogyakarta, Indonesia Phone: +62.274 .6492492 , Fax: +62.274 .581876$

Acknowledgement: This research was supported by the Indonesian government funding for research to the Ministry of Health Polytechnic Semarang. intermittent ethanol administration caused long-lasting behavioural dysfunctions, including the deficits of motor coordination as examined in rotarod tests.

It is believed that the deleterious effects of ethanol on tissues result from by-products of ethanol metabolism, including acetaldehyde, acetate, and reactive oxygen species (ROS). These harmful compounds are mainly produced through oxidative pathways which involve aldehyde dehydrogenase (ALDH), alcohol dehydrogenase (ADH), cytochrome P450 2E1 (CYP2E1), and catalase enzymes. In the brain, oxidation of ethanol by CYP2E1 produces ROS including hydroxyethyl, superoxide anion, and hydroxyl radicals, which eventually leads to the damage of nervous tissue $(11,12)$.

Hibiscus sabdariffa L. (Malvaceae) which is popularly known as roselle or red sorrel has been used as both folk beverages and traditional medicine in many regions of the world. The plants are widely grown in Central and West Africa, South Asia, South East Asia, Central America, and other regions $(13,14)$. People use the flower calyces of $H$. sabdariffa as a remedy for various types of disorders $(13,15)$. Indeed, several studies indicated that $H$. sabdariffa L. might potentially have beneficial effects in the treatment of hypertension (16), fever, liver disorders (13, 17), hepatic inflammation (18), diabetic nephropathy $(19,20)$, trypanosomiasis (21), obesity (22), diarrhoea (23), abscess (15), etc. Such effects might be exerted through different molecular pathways, one of which is through anti-oxidant defence mechanism (17). To our knowledge, not many studies have been done to explore the effects of $H$. sabdariffa to ethanol induced-oxidative damage on 
nervous system. The present study aims at investigating the possible protective effects of $H$. sabdariffa against ethanol-induced cell loss, particularly that of Purkinje cells of the cerebellum, and motor coordination deficits, using adolescent male Wistar rats as models.

\section{Materials and methods}

\section{Animals}

Forty male Wistar rats aged 21 days were used in this study. Rats are considered 'adolescent' approximately at the age of 30-42 days (24). The experimental procedures of the present study were carried out mostly during this adolescent period as described in a previous study (10). The rats were obtained from the Department of Pharmacology and Therapy, Faculty of Medicine, Universitas Gadjah Mada. The experimental procedure and animal handling was approved by Ethical Committee of the Faculty of Medicine, Universitas Gadjah Mada (approval number: KE/FK/283/EC).

The rats were divided into five groups. $\mathrm{Na} /$ wtr (negative control) group was given water orally and injected with normal saline $(\mathrm{NaCl} 0.9 \%)$ intra peritoneally. Eth/wtr (positive control) group was given water orally and ethanol $3 \mathrm{~g} / \mathrm{kg}$ body weight (ip) (10). Eth/Hsab 0.75, Eth/Hsab 1.5, and Eth/Hsab 3 groups were orally given $H$. sabdariffa solutions with different concentration ( $0.75 \mathrm{~g} ; 1.5 \mathrm{~g}$; and $3 \mathrm{~g} / 200 \mathrm{ml}$ of water, respectively). These groups were treated with the same amount and route of administration of ethanol as the Eth/wtr group. Hibiscus solutions were given half an hour prior to the injection of ethanol. All groups were treated according to their prescribed regimen every other two days for two weeks (10) following a three-day period of adaptation. Hence the treatments were given on post-natal days $25,26,29,30,33,34$, 37 and 38 (10). This pattern of treatment imitates the intermittent type of binge drinking which typically occurs in adolescents (25).

$H$. sabdariffa solutions were prepared fresh on the day of treatment by boiling three cups of $200 \mathrm{ml}$ of water containing $0.75 \mathrm{~g}, 1.5 \mathrm{~g}$, and $3 \mathrm{~g}$ calyces of Hibiscus tea, respectively, for 10 minutes. The dosage and preparation of $H$. sabdariffa solutions were determined according to commonly recommended use of the tea for a person (i.e. $1.5 \mathrm{~g}$ of $H$. sabdariffa calyces dissolved in a cup of water) (26). Solutions with a half ( $0.75 \mathrm{~g})$ and a double (3 g) amount of this standard dosage were also prepared in order to examine the effects of $H$. sabdariffa at lower and higher dosages. The volumes of Hibiscus tea given to the rats were calculated proportionally to their body weights, with an assumption that $200 \mathrm{ml}$ of Hibiscus tea is sufficient for a person with a body weight of 70 $\mathrm{kg}$. All rats were fed with rat pellets (corn starch $1875 \mathrm{kcal}$, rice starch $375 \mathrm{kcal}$, egg white $400 \mathrm{kcal}$, succrose $240 \mathrm{kcal}$, corn oil $630 \mathrm{kcal}$, agar starch $100 \mathrm{kcal}$, vitamin B 12, and minerals) and allowed to obtain water ad libitum.

\section{Revolving drum test}

The protocol of the revolving drum test referred to those described in previous studies $(27,28)$ with a slight modification. The experimental apparatus consisted of parallel cylinders with a diameter of $7 \mathrm{~cm}$ and running surfaces with the width of $8.5 \mathrm{~cm}$ each cylinder. Two side-walls were attached to the boundary of each cylinder, with a diameter of $50 \mathrm{~cm}$. The width of running surfaces allowed the rats to maintain the balance of their bodies; while at the same time it did not permit the rats to turn their body around easily to face the opposite direction. A pile of clothes was placed below the revolving drum apparatus, thus when rats fell off the cylinders they landed softly on these clothes.

The rat was placed on top of the running surface of the stationary revolving drum. It was allowed to stay there for 1 minute to familiarise with the tool, after which the rat was taken off the running surface. The revolving drum was turned on to rotate at 16 rotations per minute. The rat was returned to the top of the running surface of the drum, facing the side opposite to the direction of rotation of the revolving drum. The rat has to walk forward in order to maintain its position on the revolving drum. A stopwatch was started at the time when the rat was put on top of the running surface. The number of falls of the rat during three consecutive minutes was recorded. The stopwatch was stopped every time the rat fell, and started again once the rat was returned to the running surface. This procedure was carried out twice, i.e. prior (on post-natal day 24) and subsequent (on post-natal day 40) to the treatment.

\section{Tissue preparation}

All rats were euthanized on the next day (post-natal day 41) following the motor coordination test. They were anaesthetised with Ketalar (50 mg/ ml ketamine hydrochloride; $0.1 \mathrm{mg} / \mathrm{ml}$ phemerol chloride; PT Kalbe Farma, Jakarta, Indonesia). Once the hind limb withdrawal reflexes of the rats disappeared, trans-cardiac perfusion was carried out through the left ventricle. Isotonic saline was infused for the first few minutes, followed with a fixative consisting of approximately $250 \mathrm{ml}$ of $4 \%$ formaldehyde. The cerebella of the rats were removed, weighed, and immersed in the same fixative mixture for further 96 hours at $5{ }^{\circ} \mathrm{C}$ in refrigerator.

\section{The Estimation of the Total Number of the Cerebellar Purkinje Cells}

The cerebellar tissues of rats were sliced according to the multi-stage fractionator technique as detailed elsewhere $(29,30)$. At stage 1, each cerebellar tissue was cut parasagitally into slices with a thickness of approximately $2 \mathrm{~mm}$. A number between 1 and 2 was chosen by lottery. If number 1 was selected, every first slice was sampled for further fractionation. The sampling fraction of this first stage was $2\left(f_{1}=2\right)$. At stage 2 , the selected slices were cut into smaller slices with a thickness of about $2 \mathrm{~mm}$. A number between 1 and 2 was again determined by lottery. The sampling fraction of this second stage was $2\left(f_{2}=2\right)$. The above mentioned procedure was repeated at stage 3 , while the sampling fraction of this stage was $2\left(f_{3}=2\right)$.

The selected slices from stage 3 were then dehydrated in graded concentration of ethanol solution, cleared with toluene, and infiltrated with parafin. The tissue was subsequently embedded in parafin block. The tissue was cut using Sartorius Werke microtome with the section thickness of $6 \mu \mathrm{m}$. One of every 20 sections $\left(\mathrm{f}_{4}\right.$ $=20$ ) was chosen by lottery, mounted on slides, and stained with toluidine blue. The sections were examined under Meijii Mega Mipa 400/0 light microscope with a x10 magnification of the ob- 


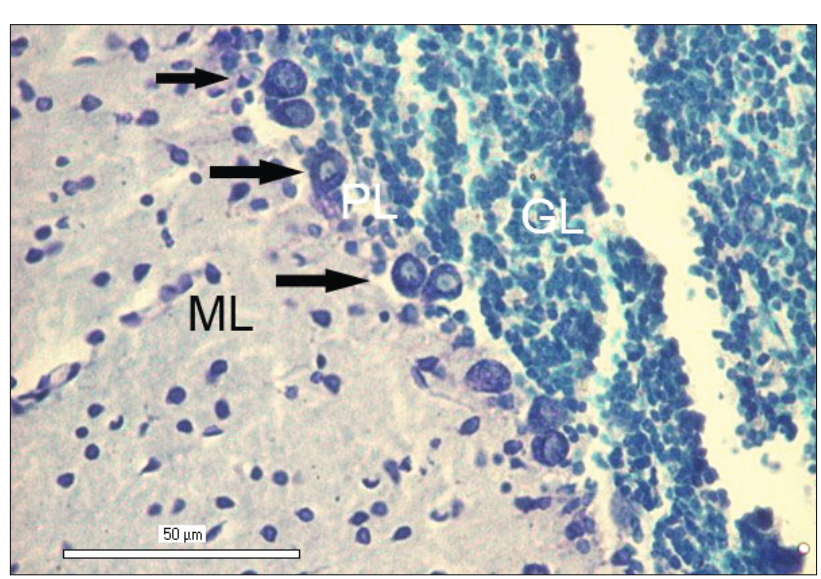

Fig. 1. The micrograph of the cerebellum with its three layers, including molecular layer (ML), Purkinje cell layer (PL), and granule cell layer (GL). The counting of the Purkinje cells was based on the presence of nucleoli (as exemplified by arrows).

jective lens. The Purkinje cells (n) were counted from these sections. The examination of the sections was carried out while the examiner was not aware of which groups the sections belonged to. Only Purkinje cells with nucleoli clearly visible under the microscope were counted (Fig. 1). The total number of Purkinje cells for each cerebellum $(\mathrm{N})$ were subsequently calculated using the following formula $(29,30)$ :

$$
N=f_{1} \times f_{2} \times f_{3} \times f_{4} \times n
$$

In order to increase the reliability of the results of Purkinje cells counting another examiner repeated the counting on several samples.

\section{Statistical analyses}

The raw data of the number of falls during revolving drum tests were transformed (31) using the formula:

$$
X(t)=\operatorname{square} \operatorname{root}(x+0.5)
$$

$\mathrm{x}=$ number of falls recorded in each trial and $\mathrm{X}(\mathrm{t})=$ transformed value.

This transformation was necessary to avoid mathematical complications arising out of some values being zero (28).

The data of the number of falls in revolving drum tests, the body weights and the total number estimate of Purkinje cells were analysed using analysis of variance (ANOVA) procedure. Independent sample t-test was performed to determine the difference of the total number estimate of Purkinje cells between treatment groups. Independent sample t-tests assessed the equality of the means. Initially, the variances associated with the variable were assumed equal. The independent sample t-tests verified this. Paired t-test was carried out to determine the difference in the number of falls in revolving drum tests prior and subsequent to treatments within groups. Statistical analyses were performed using the Statistical Package for Social Sciences version 18.0 (SPSS Science, Chicago, IL).

\section{Results}

Table 1 presents data on the total number of falls in the revolving drum tests during the 3-minute test period before and after treatment, with a one-way ANOVA of these data. The analysis of variance showed that in Eth/wtr group there was a significantly higher total number of falls after treatment than before treatment. In contrast, there was no significant difference between the total number of falls prior and subsequent to treatment in all Eth/Hsab and $\mathrm{Na} / \mathrm{wtr}$ groups.

The mean body weights of various treatment groups are shown in Table 2. Analysis of variance shows no difference in the body weights between groups before the treatment. However, there were significant reductions in body weights within the groups following the treatment.

Table 3 shows the weight of cerebellum and estimates of Purkinje cell number for all treatment groups. The cerebellar weight of Eth/wtr group was significantly lower than those of $\mathrm{Na} / \mathrm{wtr}$ and all Eth/Hsab groups $(p<0.05)$. A comparison of estimates of the number of Purkinje cells in the three Eth/Hsab subgroups to both the $\mathrm{Na} / \mathrm{wtr}$ and Eth/wtr groups -as reference estimates- using one-way ANOVA ("crude analyses") revealed that the number of Purkinje cells in these three treated groups was higher than that of $\mathrm{Na} / \mathrm{wtr}$ and Eth/wtr groups. The adjusted model of the effects of $H$. Sabdariffa of various dosages on the Purkinje cells number (statistical analyses adjusted to cerebellar weights) also confirmed that there were significantly higher estimate of the number of Purkinje cells in the Eth/Hsab subgroups relative to both $\mathrm{Na} / \mathrm{wtr}$ and Eth/wtr groups.

Tab. 1. Mean $( \pm$ SEM) of the total number of falls using the revolving drum test in various treatment group.

\begin{tabular}{lccr}
\hline Groups & \multicolumn{2}{c}{ Mean \pm SEM of the total number of falls } & \multirow{2}{*}{ p $^{*}$} \\
\cline { 2 - 3 } & before treatment & after treatment & \\
\hline $\mathrm{Na} / \mathrm{wtr}$ & $1.03 \pm 0.27$ & $1.08 \pm 0.33$ & 0.598 \\
Eth/wtr & $2.27 \pm 0.88$ & $2.75 \pm 0.66$ & 0.000 \\
Eth/Hsab 0.75 & $1.59 \pm 0.47$ & $1.61 \pm 0.42$ & 1.000 \\
Eth/Hsab 1.50 & $1.12 \pm 0.37$ & $1.01 \pm 0.34$ & 0.516 \\
Eth/Hsab 3.00 & $1.14 \pm 0.70$ & $1.03 \pm 0.47$ & 0.351 \\
\hline
\end{tabular}

$\mathrm{Na} / \mathrm{wtr}: \mathrm{NaCl} 0.9 \%$ (intraperitoneal/ip) + water (oral); Eth/wtr: ethanol (ip) + water (oral); Eth/Hsab 0.75: ethanol (ip) + H. sabdariffa $0.75 \mathrm{~g} / 200 \mathrm{ml}$ (oral); Eth/Hsab 1.50: ethanol (ip) + H. sabdariffa $1.50 \mathrm{~g} / 200 \mathrm{ml}$ (oral); Eth/Hsab 3.00: ethanol (ip) + H. sabdariffa $3.00 \mathrm{~g} / 200 \mathrm{ml}$ (oral) ${ }^{*} * \mathrm{p}$ indicates whether total number of falls is different within the groups before and after treatment (one-way ANOVA)

Tab. 2. Mean ( \pm SEM) of body weights (gram) of rats in various treatment groups.

\begin{tabular}{lccc}
\hline Group & $\begin{array}{c}\text { Number } \\
\text { of rats }\end{array}$ & $\begin{array}{c}\text { Body weight before } \\
\text { treatment (gram) }\end{array}$ & $\begin{array}{c}\text { Body weight after } \\
\text { treatment (gram)* }\end{array}$ \\
\hline $\mathrm{Na} / \mathrm{wtr}$ & 8 & $50.0 \pm 3.8$ & $48.1 \pm 3.7$ \\
$\mathrm{Eth} / \mathrm{wtr}$ & 8 & $57.0 \pm 7.1$ & $46.9 \pm 5.9$ \\
Eth/Hsab 0.75 & 8 & $37.9 \pm 4.6$ & $35.6 \pm 4.2$ \\
Eth/Hsab 1.50 & 8 & $45.0 \pm 6.5$ & $42.5 \pm 5.3$ \\
Eth/Hsab 3.00 & 8 & $55.0 \pm 3.8$ & $46.3 \pm 5.2$ \\
\hline
\end{tabular}

$\mathrm{Na} / \mathrm{wtr}: \mathrm{NaCl} 0.9 \%$ (intraperitoneal/ip) + water (oral); Eth/wtr: ethanol (ip) + water (oral); Eth/Hsab 0.75: ethanol (ip) + H. sabdariffa $0.75 \mathrm{~g} / 200 \mathrm{ml}$ (oral); Eth/Hsab 1.50: etanol (ip) + H. sabdariffa $1.50 \mathrm{~g} / 200 \mathrm{ml}$ (oral); Eth/Hsab 3.00: ethanol (ip) + H. sabdariffa $3.00 \mathrm{~g} / 200 \mathrm{ml}$ (oral) ${ }^{*} \mathrm{p}<0.001$ (One-way ANOVA indicates that there are differences in body weights prior and subsequent to treatment within groups) 
Tab. 3. Mean ( \pm SEM) cerebellar weight and Purkinje cell measures for the various treatment groups.

\begin{tabular}{|c|c|c|c|c|c|c|}
\hline \multirow[t]{2}{*}{ Groups } & \multirow[t]{2}{*}{ Cerebellar weight (mg) } & \multirow[t]{2}{*}{ Purkinje cell number $\left(10^{3}\right)$} & \multicolumn{2}{|c|}{$\mathrm{p}$ value } & \multicolumn{2}{|c|}{$\mathrm{p}$ value } \\
\hline & & & Crude* & Adjusted $\dagger$ & Crude* & Adjusted $\dagger$ \\
\hline $\mathrm{Na} /$ wtr & $231.9 \pm 12.4$ & $235.1 \pm 8.0$ & Ref & Ref & - & - \\
\hline Eth/wtr & $219.3 \pm 12.1$ & $210.6 \pm 29.9$ & 0.042 & 0.025 & Ref & Ref \\
\hline Eth/Hsab 0.75 & $231.2 \pm 9.0$ & $256.9 \pm 5.3$ & 0.000 & 0.000 & 0.001 & 0.000 \\
\hline Eth/Hsab 1.50 & $232.7 \pm 6.9$ & $276.9 \pm 15.0$ & 0.000 & 0.000 & 0.000 & 0.000 \\
\hline Eth/Hsab 3.00 & $235.8 \pm 12.9$ & $421.8 \pm 33.8$ & 0.000 & 0.000 & 0.000 & 0.000 \\
\hline
\end{tabular}

$\mathrm{Na} /$ wtr: $\mathrm{NaCl} 0.9 \%$ (intraperitoneal/ip) + water (oral); Eth/wtr: ethanol (ip) + water (oral); Eth/Hsab 0.75: ethanol (ip) + H. sabdariffa 0.75 g/200 ml (oral); Eth/Hsab 1.50: ethanol (ip) + H. sabdariffa $1.50 \mathrm{~g} / 200 \mathrm{ml}$ (oral); Eth/Hsab 3.00: ethanol (ip) $+H$. sabdariffa $3.00 \mathrm{~g} / 200 \mathrm{ml}$ (oral) $* \mathrm{p}$ indicate that Purkinje cells numbers are different between groups (one-way ANOVA); ${ }^{\dagger}$ p adjusted to cerebellar weight

\section{Discussion}

In the present study it has been found that intermittent administration of ethanol on rats throughout adolescent period caused deficits of the number of Purkinje cells of the cerebellum and motor coordination as examined in the revolving drum tests. These deficits were prevented by the administration of $H$. sabdariffa. The rats treated with ethanol and $H$. sabdariffa consistently showed higher estimated total number of Purkinje cells and better motor coordination performance compared to rats treated with ethanol only.

Studies on human subjects have reported pathological alterations of cerebellar structures, including a decrease in the number of Purkinje cells $(7,32)$, and decrease in the volume and density of Purkinje cells (5) due to chronic ethanol intoxication. Similarly, studies using animal models have shown various maladaptive responses of cerebellum to ethanol, such as increase in the densities of degenerating bodies in the Purkinje cells dendrites (6), alteration of terminal dendritic segments of Purkinje cells (8), and increase in apoptotic death of granule cells (9). It has been suggested that the mechanisms implicated in the ethanol-induced neurotoxicity of cerebellum may include excessive excitatory signalling, thiamine deficiency, glial cells dysfunctional alterations, neurotrophic factors changes, apoptosis, oxidative stress, and impaired ATP production due to mitochondrial damage (33), with oxidative stress being the major cause of neurodegeneration (34). Oxidative stress-induced neuronal death due to ethanol intoxication is mainly caused by the increase in NF- $\kappa \mathrm{B}$ proinflammatory transcription, the downstream pathway of which includes reactive oxygen species producing enzymes, and a decrease in CREB transcription. Hence, it is assumed that anti-oxidant agents that block both the decrease in proinflammatory cytokines and increase in CREB transcriptions may suppress neural degeneration due to ethanol (35).

A number of studies on the effects of $H$. sabdariffa on various disorders converge to a conclusion that $H$. sabdariffa may exert its beneficial effects through its anti-oxidant effects (13). Considerable literature reported that $H$. sabdariffa is composed of various phytochemical constituents, including phenolic compounds, anthocyanins, flavonoids, protocatechuic acid, vitamin $\mathrm{C}$ and carotenoid $(19,36)$. H. sabdariffa contains polyphenols, anthocyanins (including delphinidin-3-sambubioside, cyanidin-3-sambubioside, and delphinidin-3-glucose), and flavonoids, all of which may act as anti-oxidants $(14,36)$. The ascorbic acid content of $H$. sabdariffa (13) is higher than that of orange or mango (14). Ascorbic acid or vitamin $\mathrm{C}$ is known to be important reactive oxygen species scavengers in the non-enzymatic pathway of anti-oxidant defence mechanism (37-39).

A recent review highlighted anthocyanins, a subgroup of flavonoids (which belongs to polyphenols) consisting of more than 500 natural pigments in parts of many plants, as one possibly excellent candidate of neuroprotective agent against ethanol toxicity (34). Many investigators reported that anthocyanins improved the oxidant status of brain following ethanol exposure, as indicated by lipid peroxidation, glutathione, and anti-oxidant enzymes levels. Among types of anthocyanins which cover glycosides of cyanidin, delphinidin, malvidin, pelargonidin, peonidin, and penutidin; cyanidin is considered to be most plentiful in parts of many plants and has potent anti-oxidant capacities. Cyanidin3-glucoside $(\mathrm{C} 3 \mathrm{G})$, an example of cyanidin, with its metabolites, mainly protocatechuic acid (PCA) and aglycon cyanidin (Cy), are shown to be able to prevent $\mathrm{H}_{2} \mathrm{O}_{2}$-elicited ROS formation, antioxidant enzymes attenuation, and apoptotic progression in human neuronal-like cells SH-SY5Y (40). It is also thought that anthocyanins prevent the ethanol neurotoxicity via their anti-inflammatory activities (34). However, since the $\mathrm{C} 3 \mathrm{G}$ content was found to be minor in $H$. sabdariffa (41), it remains undetermined whether major anthocyanidins content in $H$. sabdariffa such as cyanidin-3sambubioside can be as effective against ethanol as $\mathrm{C} 3 \mathrm{G}$ in their anti-oxidant and anti-inflammatory actions. In rats model of hepatic inflammation, it has been shown that $H$. sabdariffa polyphenol extract prevented NF- $\mathrm{KB}$ translocation via its suppression on JNK and p38 MAPK protein activation, and hence inhibited the expression of COX-2 and iNOS proinflammatory proteins (18). Nevertheless, whether or not $H$. sabdariffa may actually modulate anti-oxidant enzymes, scavenge ROS, reduce oxidative damage, or modify transcriptional factors such as NF- $\mathrm{KB}$ and CREB, in the ethanol-intoxicated rats' cerebella, warrants further studies.

The results of the statistical analyses have shown that the number of Purkinje cells and the weight of cerebellum in the three groups treated with ethanol and $H$. sabdariffa were higher than in both negative (Na/wtr) and positive (Eth/wtr) controls. As it is well-known that Purkinje cells proliferate only during pre-natal life, this raises a question as to whether $H$. sabdariffa actually stimulates abnormal proliferation of Purkinje cells (42). However, morphological examinations of the specimens of the present study did not confirm the presence of any immature, atypical, or pleiomorphic forms of cells which usually characterize malignant 
growth of cells. In addition, $H$. sabdariffa is generally considered to have anti-cancer effects (13); hence it seems unlikely that it causes abnormal proliferation of Purkinje cells. The precise cause of this finding, however, is uncertain at present.

In summary, our study demonstrated that intermittent intraperitoneal ethanol administration brought about the deficits of both the motor coordination and the estimates of the total number of cerebellar Purkinje cells in male pubescent Wistar rats; and $H$. sabdariffa reversed this deterioration. Although suggestions are put forward that $H$. sabdariffa may exert its potentially beneficial effects through its anti-oxidant and anti-inflammatory mechanism, it remains uncertain as to through which molecular cascade it actually works. Thus, further studies are required to reveal such mechanism.

\section{References}

1. Ahsltröm SK, Ölsterberg EL. International perspectives on adolescent and young adult drinking. Alcohol Res Health 2004/2005; 28: 258-268.

2. Chen CM, Dufour MC, Yi H-Y. Alcohol consumption among young adults ages 18-24 in the United States: Results from the 2001-2002 NESARC survey. Alcohol Res Health 2004/2005; 28: 269-280.

3. Oscar-Berman M, Shagrin B, Evert DL, Epstein C. Impairments of brain and behavior. The neurological effects of alcohol. Alcohol Health Res World 1997; 21: 65-75.

4. White AM, Truesdale MC, Bae JG et al. Differential effects of ethanol on motor coordination in adolescent and adult rats. Pharmacol Biochem Behav 2002; 73: 673-677.

5. Andersen BB. Reduction of Purkinje cell volume in cerebellum of alcoholics. Brain Res 2004; 1007: 10-18.

6. Dlugos CA. Ethanol-related increases in degenerating bodies in the Purkinje neuron dendrites of aging rats. Brain Res 2008; 1221: 98-107.

7. Karhune PJ, Erkinjuntti T, Laippala P. Moderate alcohol consumption and loss of cerebellar Purkinje cells. BMJ 1994; 308: 1663-1667.

8. Pentney RJ, Dlugos CA. Cerebellar Purkinje neurons with altered terminal dendritic segments are present in all lobules of the cerebellar vermis of ageing, ethanol-treated F344 rats. Alcohol Alcohol 2000; 35: 35-43.

9. Luo J. Mechanisms of ethanol-induced death of cerebellar granule cells. Cerebellum 2012; 11: 145-154.

10. Pascual M, Blanco AM, Cauli O, Miñarro J, Guerri C. Intermittent ethanol exposure induces inflammatory brain damage and causes longterm behavioural alterations in adolescent rats. Eur J Neurosci 2007; 25 : $541-550$.

11. Deitrich R, Zimatkin S, Pronko S. Oxidation of ethanol in the brain and its consequences. Alcohol Res Health 2006; 29: 266-273.

12. Zakhari S. Overview: how is alcohol metabolized by the body? Alcohol Res Health 2006; 29: 245-254.

13. Ali BH, Wabel NA, Blunden G. Phytochemical, pharmacological and toxicological aspects of Hibiscus sabdariffa L.: a review. Phytother Res 2005; 19: 369-375.

14. Fasoyiro SB, Ashaye OA, Adeola A, Samuel FO. Chemical and storability of fruit-flavoured (Hibiscus sabdariffa) drinks. World J Agric Sci 2005; 1 : 165-168.
15. Olaleye MT. Cytotoxicity and antibacterial activity of methanolic extract of Hibiscus sabdariffa. J Med Plants Res 2007; 1: 9-13.

16. McKay DL, Chen C-YO, Saltzman E, Blumberg JB. Hibiscus sabdariffa L. tea (tisane) lowers blood pressure in prehypertensive and mildly hypertensive adults. J Nutr 2010; 140: 298-303.

17. Usoh IF, Akpan EJ, Etim EO, Farombi EO. Antioxidant actions of dried flower extracts of Hibiscus sabdariffa L. on sodium arsenite - induced oxidative stress in rats. Pakistan J Nutr 2005; 4: 135-141.

18. Kao E-S, Hsu J-D, Wang C-J, Yang S-H, Cheng S-Y, Lee H-J. Polyphenols extracted from Hibiscus sabdariffa L. inhibited lipopolysaccharideinduced inflammation by improving antioxidative conditions and regulating cyclooxigenase-2 expression. Biosci Biotechnol Biochem 2009; 73: 385-390.

19. Lee W-C, Wang C-J, Chen Y-H et al. Polyphenol extracts from Hibiscus sabdariffa Linnaeus attenuate nephropathy in experimental type 1 diabetes. J Agric Food Chem 2009; 57: 2206-2210.

20. Wang S-C, Lee S-F, Wang C-J, Lee C-H, Lee W-C, Lee H-J. Aqueous extract from Hibiscus sabdariffa Linnaeus ameliorate diabetic nephropathy via regulating oxidative status and $\mathrm{Akt} / \mathrm{Bad} / 14-3-3$ gamma in an experimental animal model. eCAM 2011; 2011: 1-9.

21. Umar IA, Maryoms NG, Daikwob E et al. The effect of aqueous extracts of Hibiscus sabdariffa (sorrel) calyces on heamatological profile and organ pathological changes in trypanasoma congolense - infected rats. Afr J Trad CAM 2009; 6: 585 - 591.

22. Carvajal-Zarrabal O, Hayward-Jones PM, Orta-Flores Z et al. Effect of Hibiscus sabdariffa L. dried calyx ethanol extract on fat absorption-excretion, and body weight implication in rats. J Biomed Biotech 2009; 2009: 1-5.

23. Ali MK, Ashraf A, Biswas NN, Karmakar UK, Afroz S. Antinociceptive, anti-inflammatory and antidiarrheal activities of ethanolic calyx extract of Hibiscus sabdariffa Linn. (Malvaceae) in mice. J Chinese Integr Med 2011; 9: 626-631.

24. Spear L. Modeling adolescent development and alcohol use in animals. Alcohol Res Health 2000; 24: 115-123.

25. Tur JA, Puig MS, Pons A, Benito E. Alcohol consumption among school adolescents in Palma de Mallorca. Alcohol Alcohol 2003; 38: 243-248.

26. United Nations Industrial Development Organization ICfSaHT. Database on important medicinal and aromatic plants, http://www.ics. trieste.it/MedicinalPlant/MedicinalPlant_References.aspx?id=101 (2008, accessed 25 February 2008).

27. Smart JL, Bedi K. Early life undernutrition in rats. 3. Motor performance in adulthood. Br J Nutr 1982; 47: 439-444.

28. Partadiredja G, Bedi KS. Mice undernourished before, but not after, weaning perform better in motor coordination and spatial learning tasks than well-fed controls. Nutr Neurosci 2011; 14: 129-137.

29. Gundersen HJ. Stereology of arbitrary particles. A review of unbiased number and size estimators and the presentation of some new ones, in memory of William R. Thompson. J Microsc 1986; 143: 3-45.

30. Miki T, Harris SJ, Wilce P, Takeuchi Y, Bedi KS. The effect of the timing of ethanol exposure during early postnatal life on total number of Purkinje cells in rat cerebellum. J Anat 1999; 194: 423-431.

31. Sokal RR, Rohlf FJ. Biometry. The principles and practice of statistics in biological research. 3 ed. 1995. New York: W. H. Freeman \& Co. 887 . 


\section{9-114}

32. Lee Y, Rowe J, Eskue K, West JR, Maier SE. Alcohol exposure on postnatal day 5 induces Purkinje cell loss and evidence of Purkinje cell degradation in lobule I of rat cerebellum. Alcohol 2008; 42: 295-302.

33. Jaatinen P, Rintala J. Mechanisms of ethanol-induced degeneration in the developing, mature, and aging cerebellum. Cerebellum 2008: 332-347.

34. Chen G, Luo J. Anthocyanins: are they beneficial in treating ethanol neurotoxicity? Neurotox Res 2010; 17: 91-101.

35. Crews FT, Nixon K. Mechanisms of neurodegeneration and regeneration in alcoholism. Alcohol Alcohol 2009; 44: 115-127.

36. Kuriyan R, Kumar DR, Rajendran R, Kurpad AV. An evaluation of the hypolipidemic effect of an extract of Hibiscus Sabdariffa leaves in hyperlipidemic Indians: a double blind, placebo controlled trial. BMC Complement Altern Med 2010; 10: 1-8.
37. Chaudiere J, Ferrari-Iliou R. Intracellular antioxidants: from chemical to biochemical mechanisms. Food Chem Toxicol 1999; 37: 949-962.

38. Fang YZ, Yang S, Wu G. Free radicals, antioxidants, and nutrition. Nutrition 2002; 18: 872-879.

39. Knight JA. The biochemistry of aging. Adv Clin Chem 2000; 35: 1-62.

40. Tarozzi A, Morroni F, Hrelia S et al. Neuroprotective effects of anthocyanins and their in vivo metabolites in SH-SY5Y cells. Neurosci Lett 2007; 424: 36-40.

41. Frank T, Janßen M, Netzel M et al. Pharmacokinetics of anthocyanidin-3-glycosides following consumption of Hibiscus sabdariffa L. extract. J Clin Pharmacol 2005; 45: 203-210.

42. Smart JL. Vulnerability of developing brain to undernutrition. Ups J Med Sci 1990; 48: 21-41. 